\title{
Variations in carbon isotopic composition in the subcontinental lithospheric mantle beneath the Yangtze and North China Cratons: Evidence from in-situ analysis of diamonds using SIMS
}

\author{
CHEN Hua ${ }^{1}$, QIU ZhiLi ${ }^{2 *}$, LU TaiJin ${ }^{1}$, STERN Richard ${ }^{3}$, STACHEL Thomas $^{3}$, SUN Yuan ${ }^{2}$, \\ ZHANG Jian ${ }^{1}, \mathrm{KE} \mathrm{Jie}^{1}$, PENG ShuYi ${ }^{2}$ \& QIN SheCai ${ }^{2}$ \\ ${ }^{1}$ Beijing Institute of Gemology, National Gems \& Jewelry Technology Administrative Center, Beijing 100013, China; \\ ${ }^{2}$ Department of Earth Science, Sun Yat-sen University, Guangzhou 510275, China; \\ ${ }^{3}$ Canadian Centre for Isotopic Microanalysis, University of Alberta, Edmonton T6E 2E5, Canada
}

Received June 28, 2012; accepted September 19, 2012; published online November 23, 2012

\begin{abstract}
The components and evolution of subcontinental lithospheric mantle beneath the North China Craton and the Yangtze Craton is a current topic in the geological study of China and the carbon isotopic composition of diamond is one of the most direct probes into cratonic lithospheric mantle processes. In this paper, in-situ SIMS (Secondary Ion Mass Spectrometry) techniques were used to analyze the carbon isotope compositions at different internal growth zones of diamonds from Shandong and Liaoning in the North China Craton and Hunan in the Yangtze Craton. It was found that the carbon isotopic range of diamonds from the North China Craton are rather distinct from those of the Yangtze Craton; the former has a range of $-6.0 \%$ o to $-2.0 \%$ (relative to VPDB) with an average value of $-3.0 \%$ in their core areas, which is consistent with global peridotitic diamonds; the diamonds from the Yangtze Craton, however, have a carbon isotopic range from $-8.6 \%$ to $-3.0 \%$ with an average value of $-7.4 \%$ in their core areas, being more consistent with global eclogitic diamonds. The variations of carbon isotope ratios between different internal growth zones in individual diamonds were different in the three diamond localities studied. There was a clear correlation between changes in carbon isotopic composition and phases of diamond dissolution and new growth, while no correlation was observed between $\delta^{13} \mathrm{C}$ and internal inclusions. The variations suggest that the carbon isotopic compositions of mantle fluids were changing during the process of diamond crystallization, and that the heterogeneity of the carbon isotopic composition in mantle carbon reservoirs was a more important factor than carbon isotope fractionation in controlling the carbon isotopic compositions and their variation in diamonds. In addition, the preliminary results of in-situ nitrogen analyses demonstrated that the variation of carbon isotopic compositions between the core and outer growth zones does not correlate with nitrogen abundances, implying either that diamonds crystallized in an open environment or that the carbon isotopic composition and nitrogen contents in mantle fluids were controlled by other, not yet understood factors. The experimental results provide hints that the isotopic composition of carbon and its original sources were different in metasomatic fluids controlling diamond formation in the mantle beneath the North China Craton and the Yangtze Craton.
\end{abstract}

diamonds, carbon isotopic composition, in-situ SIMS analysis, subcontinental lithospheric mantle, North China Craton, Yangtze Craton

Citation: Chen H, Qiu Z L, Lu T J, et al. Variations in carbon isotopic composition in the subcontinental lithospheric mantle beneath the Yangtze and North China Cratons: Evidence from in-situ analysis of diamonds using SIMS. Chin Sci Bull, 2013, 58: 99-107, doi: 10.1007/s11434-012-5509-0

The carbon isotopic compositions of diamonds provide useful information for investigating mantle carbon flux and

*Corresponding author (email: qiuzhili@mail.sysu.edu.cn) its changes in the lithospheric mantle, and hence for studying deep materials and metasomatism through mantle fluids [1-3]. In China, there are three major diamond localities, (1) Mengyin in Shandong Province, (2) Wafangdian in Liao- 
ning Province, and (3) the Ruanshui River basin in Hunan Province, which are geologically located in the North China Craton and the Yangtze Craton, respectively [4-6]. Since the 1950s, extensive investigations on carbon isotopes of diamond have been performed [1-13]. It was recognized that peridotitic diamonds and eclogitic diamonds have rather distinct ranges of carbon isotopes: while the carbon isotopic compositions of peridotitic diamonds or graphite are, by comparison, ${ }^{13} \mathrm{C}$-enriched and record narrow ranges, eclogitic diamonds may be strongly depleted in ${ }^{13} \mathrm{C}$, and its range in carbon isotopic composition is broader [2,7-13]. The carbon isotopic distribution of diamond is not only affected by mantle carbon isotopic fractionation, but is also related to its carbon reservoir and source. The huge variation in the $\delta^{13} \mathrm{C}$ distribution of diamond towards strongly negative values is regarded as resulting from crustal organic carbon recycled into the mantle via subduction. In-situ analyses with SIMS indicated that carbon isotopes in diamond depict complex growth zones. Moreover, complicated relations exist between carbon isotopes and nitrogen content as well as nitrogen isotopes in different occurrences [14-22].

Research on carbon isotopes of diamond developed rather late in China with the method and achievement lagging behind; the earliest carbon isotopic ratio measurements were completed by destructive vacuum combustion employing a MAT-251 mass spectrometer [23]. Zhang et al. [24] published the most valuable paper in 2009 in which they presented analyses of carbon isotope compositions, analyzed by EA2IRMS (Isotope Ratio Mass Spectrometry connected with an Elemental Analyzer), of diamonds from Mengyin (Shandong Province) and Fuxian (Liaoning Province). It was found that there were ubiquitous layers with distinct carbon isotopic compositions within individual diamonds but the overall diamonds in the North China Craton have carbon isotopic composition $(-11.2 \%$ o to $-0.2 \%$ o similar to diamonds of peridotitic paragenesis worldwide [5], implying a deep mantle source of their carbon. Compared to the North China Craton, few studies on the carbon isotopic composition of diamonds from the Yangtze Craton have been performed. Liu et al. [25] reported that diamonds from the Yangtze Craton display a wider range ( $-22.2 \%$ o to $-2.5 \%$ o of carbon isotopic compositions, possibly implying that the diamonds from the two cratons could have different carbon sources or formation mechanisms.

So far, only average values of carbon isotopic compositions for single diamonds are available on China's diamonds, which cannot provide information on the variations of carbon isotope compositions during their formation. In order to understand the internal variation in carbon isotopic compositions and the factors influencing these variations during diamond formation beneath the North China Craton and the Yangtze Craton, in this paper, we present carbon isotope data for 123 analytical points and nitrogen abundances for 42 analytical points, obtained by means of in-situ SIMS analyses of 11 diamonds with different internal growth structures from the North China Craton and the Yangtze Craton.

\section{Samples and methods}

Eleven near gem and gem-grade rough diamonds were collected: four from Pipe 50 in Liaoning Province, four from Pipe I in Shandong Province, and three from an alluvial deposit in Hunan Province, China. The samples are 2-5 mm in size with well developed octahedral or dodecahedraloctahedral shapes, which can be easily cut into slices along $\{111\}$ and $\{110\}$ planes. The diamond samples were nearly colorless to light brown and contained few inclusions, except for a subset of inclusion-bearing diamonds that were selected for a separate inclusion study. Slabs with thicknesses of 0.5 to $1 \mathrm{~mm}$ were cut with an uncertain crystallographic orientation from three samples. All samples ( Figure 1) selected for carbon isotope analysis are listed in Table 1.

In order to study variations in the carbon isotope composition of diamonds during their natural growth processes, we selected appropriate samples with typical internal growth structures for each locality. Cathodoluminescence (CL) and DiamondView $^{\mathrm{TM}}$ fluorescence images of the diamonds were obtained to analyze their internal growth structures, dissolution patterns, as well as plastic deformation related features $[26,27]$.

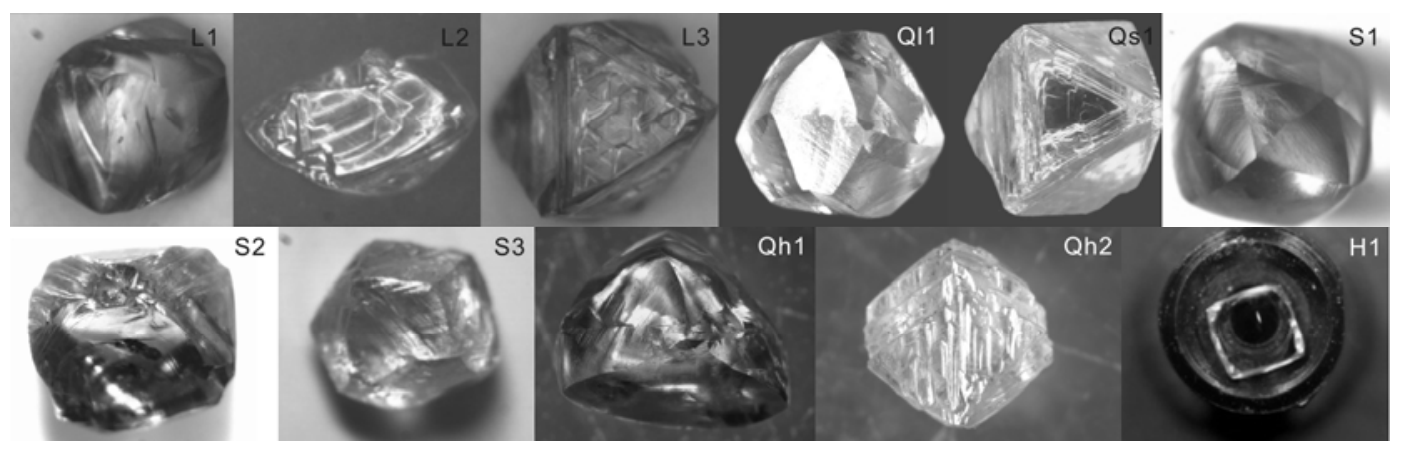

Figure 1 The studied 11 diamond samples from Liaoning, Shandong, and Hunan provinces. 
Table 1 General features of the studied 11 diamond samples

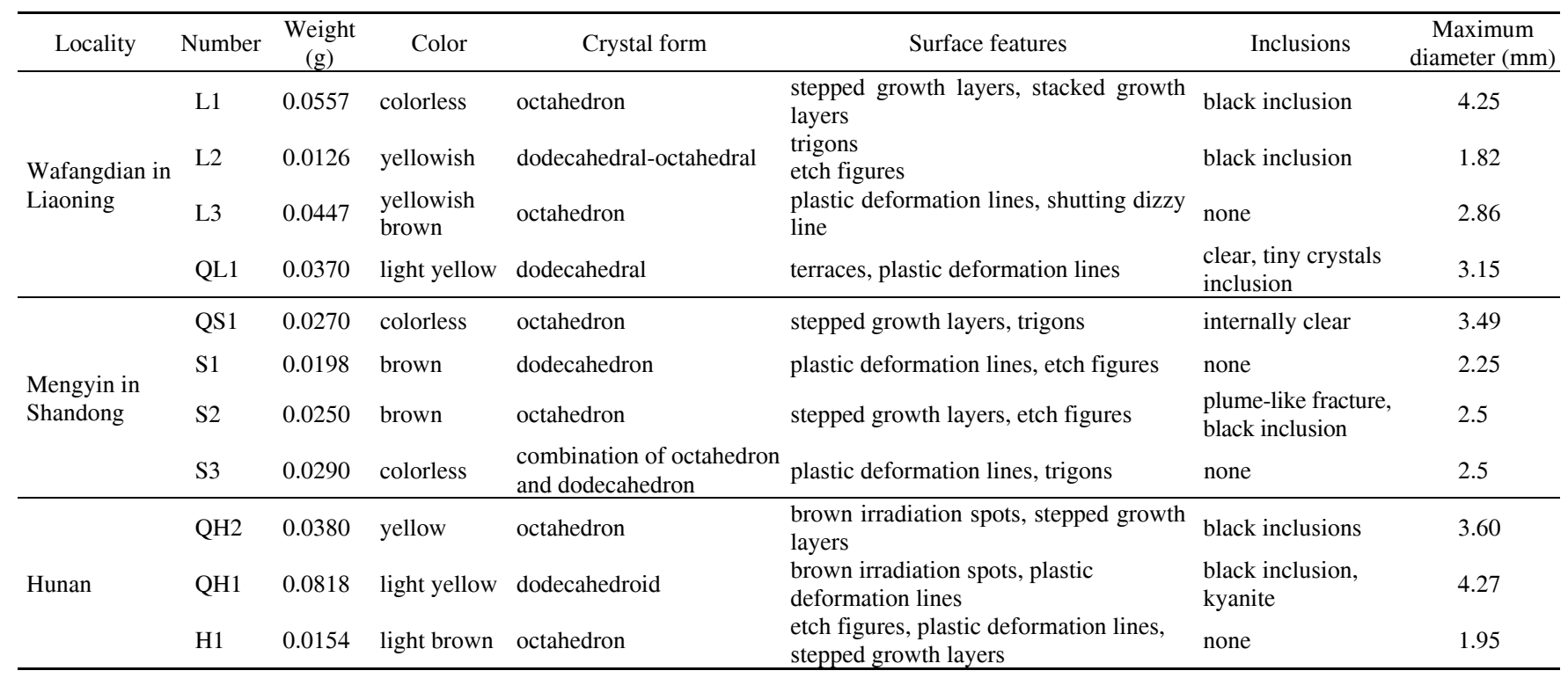

Carbon isotope analyses and nitrogen abundances were carried out using SIMS (Secondary Ion Mass Spectrometry) at CCIM, University of Alberta, Canada. The SIMS instrument used has a relative detection limits on the $\sim$ ppb level, a spatial resolution of $\sim 1-30 \mu \mathrm{m}$, a depth resolution of $0.01-5$ $\mu \mathrm{m}$, and a maximum mass resolution of 40000. For our SIMS analyses of $\mathrm{C}$-isotope and $\mathrm{N}$-abundances, a $\sim 4$ nA 20 $\mathrm{keV} \mathrm{Cs}^{+}$primary beam was utilized. Charge compensation with the electron gun was found unnecessary for the diamonds studied. Negative secondary ions of ${ }^{12} \mathrm{C}^{-}$and ${ }^{13} \mathrm{C}^{-}$ were measured simultaneously in dual Faraday cups, with mass resolution sufficient to resolve isobaric interference by ${ }^{12} \mathrm{CH}^{-}$, and determined over $80 \mathrm{~s}$ total count time. Typical count rates for ${ }^{13} \mathrm{C}^{-}$were $3 \times 10^{7} \mathrm{cps}$, resulting in typical counting uncertainty per spot of $0.03 \%$ ( $68 \%$ confidence). Instrumental mass fractionation $(\sim-20 \%$ ) and spot-spot repeatability (standard deviation less than or equal to $0.05 \%$ ) were determined by repeated analysis (after every 4th unknown) of CCIM diamond reference material S0011 $\left(\delta^{13} \mathrm{C}\right.$ $(\mathrm{VPDB})=-22.58 \%$, University of Alberta). Propagated uncertainties reflect all of these factors, and are typically $\pm 0.15 \%$ o (95\% confidence). For $\mathrm{N}$-abundances, determined on the same spots as $\mathrm{C}$-isotopes, the molecular ions ${ }^{12} \mathrm{C}^{14} \mathrm{~N}^{-}$ (nitrogen) and ${ }^{12} \mathrm{C}^{12} \mathrm{C}^{-}$(internal standard) were determined simultaneously via an electron multiplier and Faraday cup combination, respectively, both at mass resolution $\sim 7000$ sufficient to resolve spectral interferences. The sensitivity factor for nitrogen abundance was calibrated by analysis of CCIM reference diamond S0011 (for which an N-abundance of 420 ppm had been determined by FTIR) at the start and end of each analytical session.

For analysis, the diamond slices were mounted in an indium metal target, adjacent to pieces of diamond reference material for purposes of calibration, and then coated with a 5-nm-thick pure gold film. These gold-plated diamonds were firstly imaged by Cathodoluminescence, and then they were coated with a 20-nm-thick pure gold film for the second time for the measurement of carbon isotope ratios and nitrogen abundances. The analytical points for carbon isotope ratio measurements were arranged based on CL images, transecting growth zones from core to rim within a diamond (Figure 2).

\section{Results}

\subsection{Primitive cores of diamonds and their carbon isotope ratios and $\mathrm{N}$ abundance}

Synthetic diamonds are generally grown under high pressure and temperature employing a crystal seed [28-30]. For natural diamond growth, there is not a unified understanding if a seed is required, and if so, the nature of the seed [31-33]. With one exception (Liaoning L2), all diamonds discussed here contained a primitive core area at the center within each diamond which appeared different from the outer growth zones in CL images, and the outer growth zones formed around the core area and were clearly influenced in shape by the core area. These core areas, therefore, likely can be considered as primitive crystal seeds for diamond crystallization, and some of them had even finer crystal seeds themselves [34]. Some references reported that the difference in age between the core and the outermost growth zone for one diamond was $1.2 \mathrm{Ga}$, and that for Liaoning diamonds this time difference was $0.6-0.7 \mathrm{Ga}$ $[35,36]$. Therefore, the carbon isotope ratios and $\mathrm{N}$ abundances measured in core areas could represent those of 

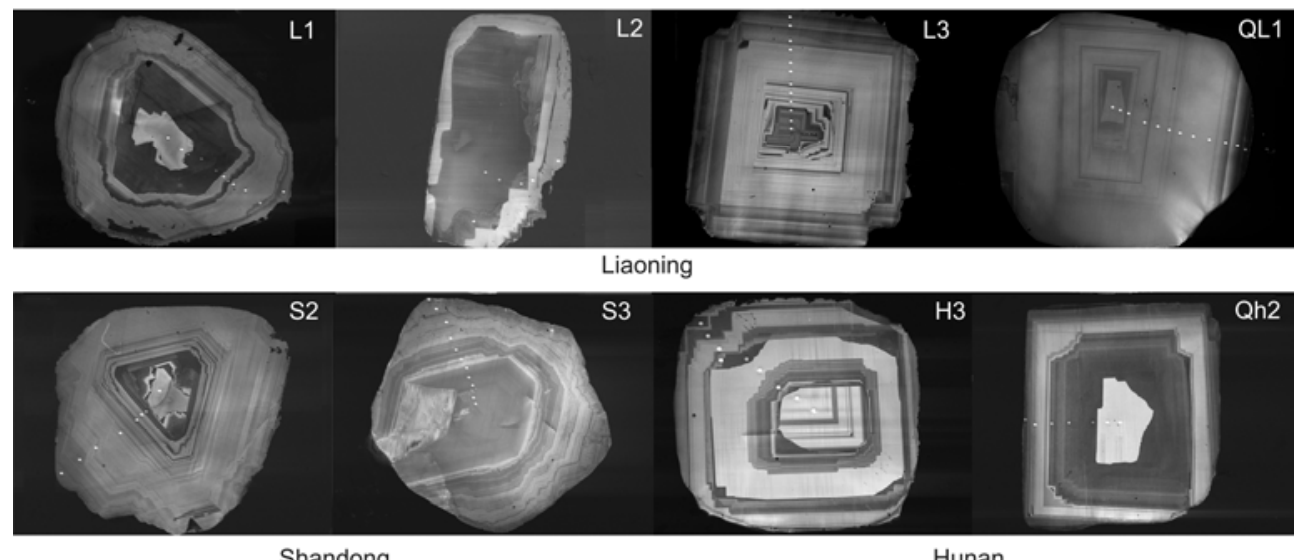

Shandong

Hunan

Figure 2 Cathodoluminescence images and analytical spots for the diamond plates from Liaoning, Shandong, and Hunan provinces.

mantle sources during early stages of craton stability (Table 2).

The CL images indicate that only a few diamonds, e.g. QH1 and H1 from Hunan, contained primitive cores with regular crystal faces and outer growth zones overgrowing the cores in a continuous fashion. Most diamonds, such as $\mathrm{S} 2$ in Figure 3, have irregular fragments as cores, which are different from growth zones around them in CL images. Table 2 shows that $\mathrm{N}$ abundances of diamonds in the cores vary strongly among diamonds from the three localities; on the contrary, carbon isotopes of diamonds in the core areas are limited to a narrow range, especially for diamonds from the same craton. Specifically, carbon isotope ratios of diamonds in the Yangtze Craton were dominated by isotopically light carbon, with an average $\delta^{13} \mathrm{C}$ of $-7.4 \%$ for two Hunan samples, while diamonds from the North China Craton were dominantly heavy in their carbon isotope compositions, with an average $\delta^{13} \mathrm{C}$ of $-3.0 \%$ o for both three Liaoning and three Shandong diamonds. This suggests that during initial diamond growth, the carbon available in the mantle beneath the North China Craton was ${ }^{13} \mathrm{C}$ enriched (relative to the average $\delta^{13} \mathrm{C}$ of $-5.5 \%$ or for global mantle) and depleted in ${ }^{13} \mathrm{C}$ beneath the Yangtze Craton.

\subsection{Growth zones of diamonds and their relationship to carbon isotope ratios and $\mathrm{N}$ abundance}

Carbon isotope ratios were determined for 123 points on 11 diamonds from three localities (Table 3 and Figure 3). The results show that $\delta^{13} \mathrm{C}$ ranges between $-8.6 \%$ and $-2.0 \%$ o with an average of $-4.6 \%$. This is in good agreement with the main range between $-9 \%$ and $-2 \%$ in carbon isotope ratios and an average value of about $-5 \%$ for peridotitic diamonds worldwide [2,7,14,37], which are assumed to precipitate from mantle carbon. The carbon isotopes of the studied diamonds from three localities in China are thus interpreted to reflect the isotopic signature of their mantle source. Between core areas and outer growth zones within individual diamond or among separate diamonds, there are no correlations between the intensity of cathode luminescence and carbon isotope ratios, in accordance with the results of previous studies [19,38,39].

The $\mathrm{N}$ abundances of Hunan single diamonds cover a smaller range than those from Shandong and Liaoning (Table 3). The $\mathrm{N}$ abundances of single diamonds in different growth zones from all three localities show no clear correlation with changes in carbon isotope compositions from the

Table 2 The carbon isotope ratios and $\mathrm{N}$ abundances measured at primitive core areas inside diamonds of Liaoning, Shandong, and Hunan

\begin{tabular}{|c|c|c|c|c|c|c|c|c|c|}
\hline \multirow{2}{*}{ Locality } & \multirow{2}{*}{ Sample No. } & \multicolumn{4}{|c|}{$\mathrm{N}$ abundance (atomic ppm) } & \multicolumn{4}{|c|}{$\delta^{13} \mathrm{C}$ relative to $\mathrm{VPDB}(\% o)$} \\
\hline & & Point 1 & Point 2 & Point 3 & Average & Point 1 & Point 2 & Point 3 & Average \\
\hline \multirow{2}{*}{ Liaoning } & L1 & 929 & 372 & - & 651 & -2.76 & -2.60 & - & -2.68 \\
\hline & QL1 & - & - & - & - & -3.50 & -3.34 & - & -3.42 \\
\hline \multirow{3}{*}{ Shandong } & $\mathrm{S} 1$ & 982 & 1090 & 967 & 1013 & -3.11 & -2.95 & -2.80 & -2.95 \\
\hline & $\mathrm{S} 2$ & - & - & - & - & -2.97 & - & - & -2.97 \\
\hline & QS1 & - & - & - & - & -3.30 & -3.00 & - & -3.15 \\
\hline \multirow{3}{*}{ Hunan } & H1 & 273 & 417 & - & 345 & -7.48 & -7.70 & - & -7.59 \\
\hline & QH1 & - & - & - & - & -7.22 & - & - & -7.22 \\
\hline & QH2 & - & - & - & - & -3.36 & -3.41 & - & -3.39 \\
\hline
\end{tabular}




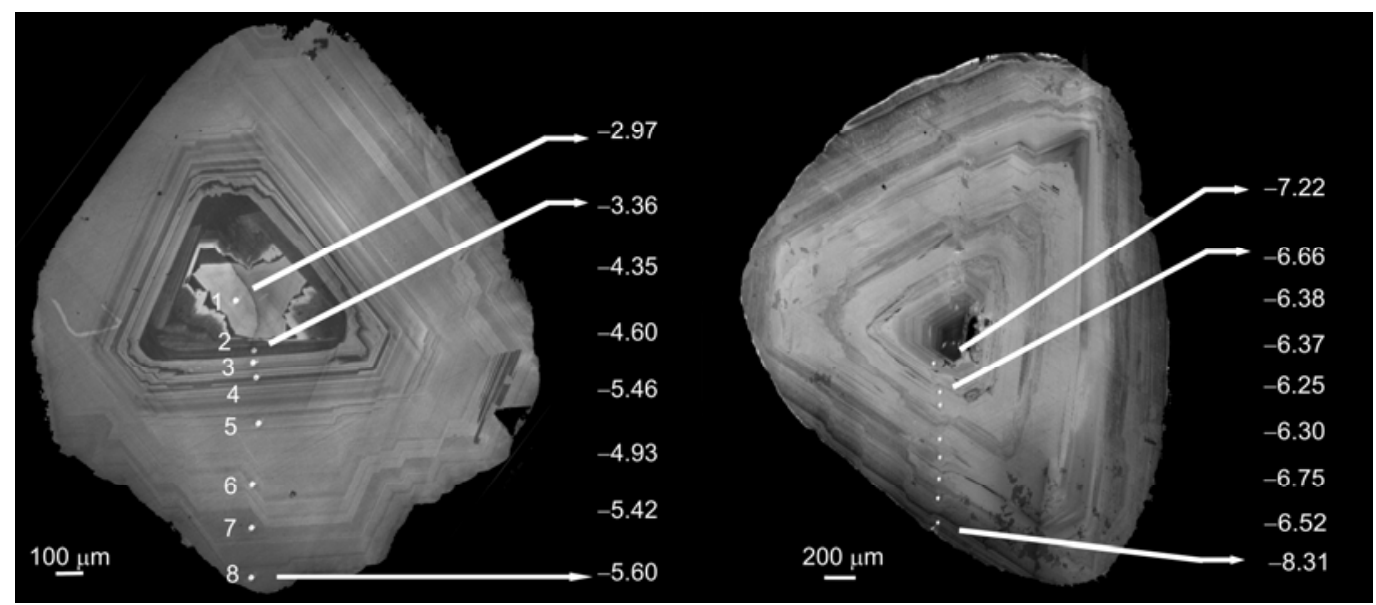

Figure 3 Variation of carbon isotope ratios at the primitive core area and outer growth zones of diamonds $\left(\delta^{13} \mathrm{C}\right.$ in \%o).

Table 3 Carbon isotope ratios and $\mathrm{N}$ abundances measured across growth zones of diamonds from Liaoning, Shandong, and Hunan

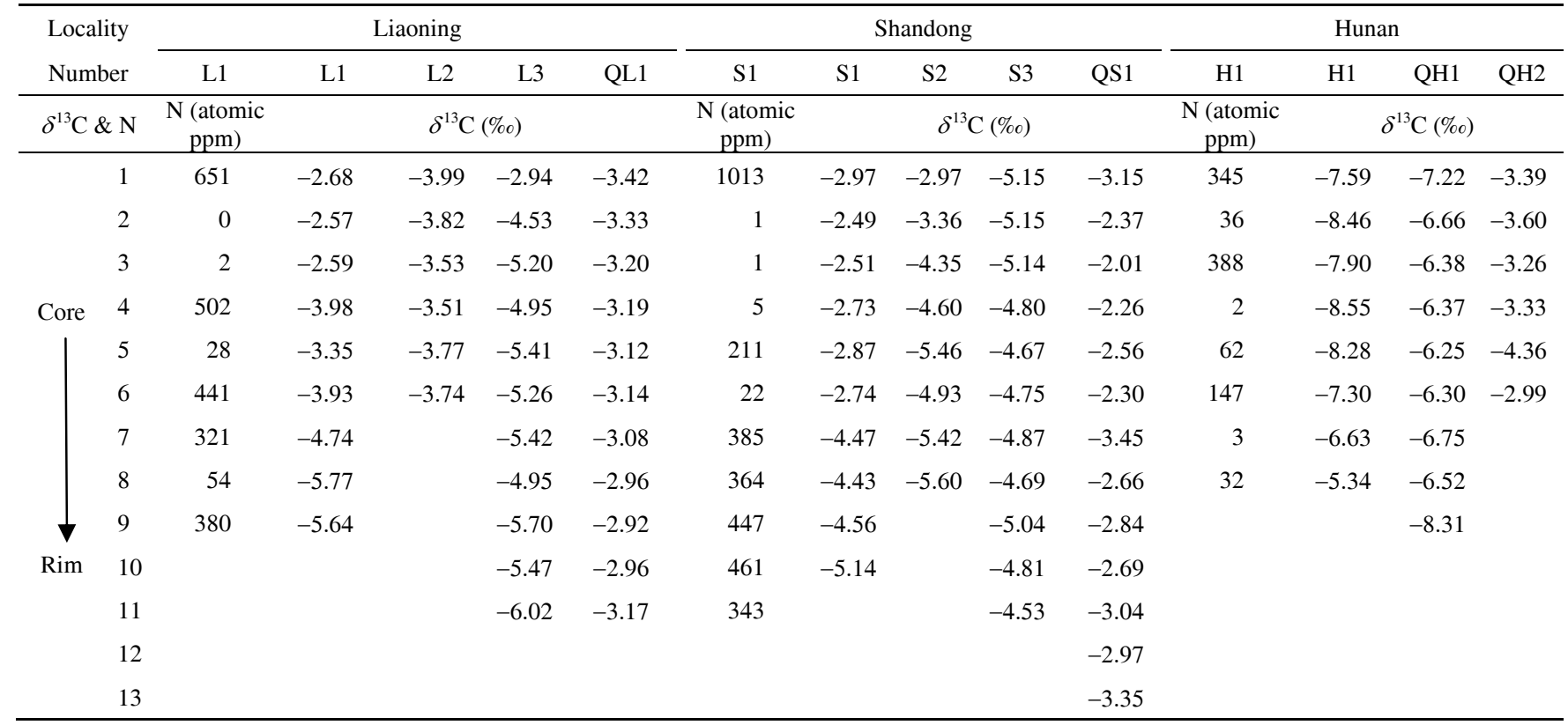

core to rim (Figure 4).

\section{Discussion}

\subsection{Variations of carbon isotopes in growth zones and inferences on deep geological process in mantle}

For Liaoning diamonds, carbon isotope ratios range between $-6.0 \%$ and $-2.6 \%$ with an average of $-3.9 \%$ (Table 3 and Figure 3 ). This range is basically similar to the studies reported by Cartigny et al. [37] for 55 diamonds of peridotitic paragenesis from Pipe-50 in Liaoning (range $-6.2 \%$ to $0.8 \%$; average $-3.5 \% \circ \pm 1.5 \%$ ) , and those by Zhang et al. [24] (range $-5.0 \%$ o to $-1.4 \%$ ), but the range of heavier $\delta^{13} \mathrm{C}$ is slightly narrower. There are three trends in carbon isotope ratios from core to rim: increasing and then decreasing for L2 and QL1; an irregular increase and then decrease for L3; and repeated increases and decreases for L1. Irrespective of the overall trend, all diamonds first show an increase and then a decrease in carbon isotope ratios, and for most diamonds crystallization ends with a rim that is depleted in ${ }^{13} \mathrm{C}$. Table 4 shows that the maximum difference between highest and lowest $\delta^{13} \mathrm{C}$ value within single diamonds is $3.2 \%$, seen for diamond L1 which also shows stages of dissolution between growth phases. The smallest internal variation of only $0.5 \%$ was observed for the black inclusion-bearing diamond L2 and diamond QL1.

For Shandong diamonds, carbon isotope ratios determined on 56 points range between $-5.6 \%$ and $-2.0 \%$ with an average of $-3.6 \%$. This range is narrower than the previously 

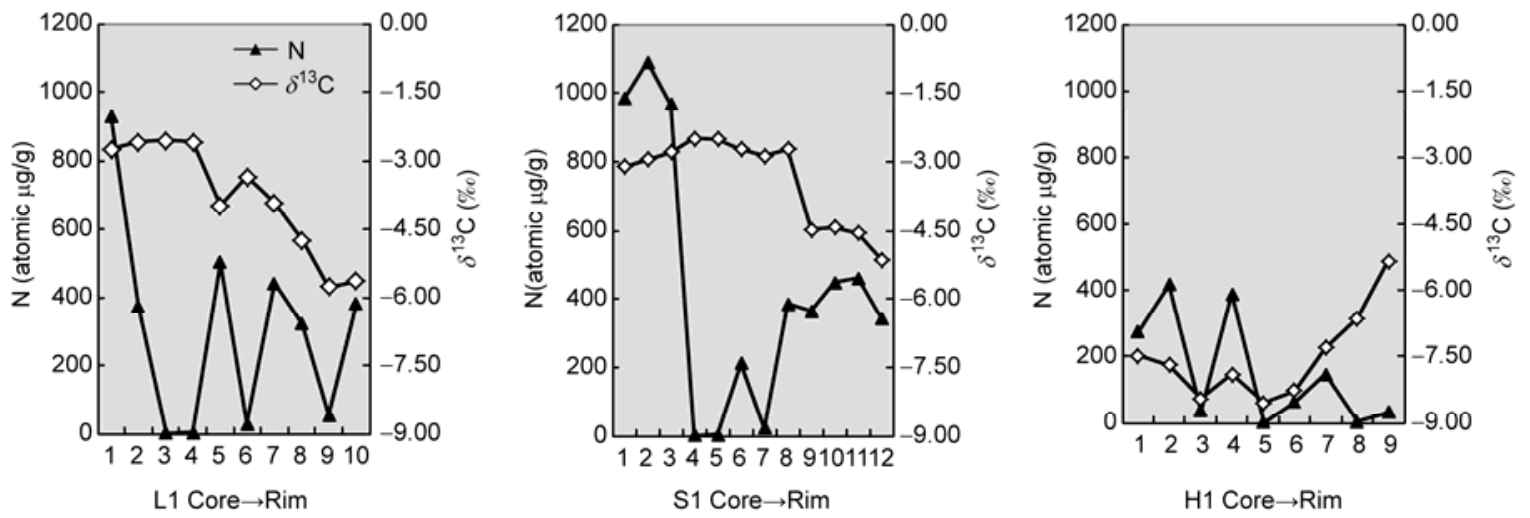

Figure 4 Variations of carbon isotope ratios and $\mathrm{N}$ abundances (atomic ppm) from core to rim for diamonds from Liaoning (L1), Shandong (S1), and Hunan (H1) (Table 3).

observed for Shandong diamonds (range $-6.4 \%$ to $-0.4 \%$ ) by Zhang et al. [24]. Four different cores to rims trends in $\delta^{13} \mathrm{C}$ were observed: increasing and then decreasing for $\mathrm{S} 1$; decreasing, increasing and then again decreasing for S2; increasing, decreasing and increasing for $\mathrm{S} 3$; and two cycles of first increasing and then decreasing for QS1. All diamonds except S2 first show an increase and then a decrease in carbon isotope ratios during their initial crystallization process. Most diamonds (83\%) ended their crystallization with lighter carbon isotope compositions at the outermost growth zone. The maximum within-diamond difference is $-2.8 \%$, observed for inclusion-bearing diamond $\mathrm{S} 1$, and the minimum internal variation $(0.6 \%$ ) was derived from internally clean diamond $\mathrm{S} 3$.

For Hunan diamonds, $\delta^{13} \mathrm{C}$ ranges from $-8.6 \%$ to $-3.0 \%$ o with an average of $-6.1 \%$. The maximum internal variability, $-3.2 \%$, was observed for diamond $\mathrm{H} 1$, which was cut into a plate parallel to $\{100\}$ and contains evidence for intermittent growth interrupted by a phase of dissolution; this diamond is inclusion free. There are two types of variations in carbon isotope ratios from core to rim: gradually decreasing and then increasing $\delta^{13} \mathrm{C}$ for $\mathrm{H} 1$ and $\mathrm{QH} 2$, and gradually increasing and then decreasing $\delta^{13} \mathrm{C}$ for $\mathrm{QH} 1$. In contrast to Liaoning and Shandong diamonds, two Hunan diamonds show an overall trend of first decreasing and then increasing $\delta^{13} \mathrm{C}$, remaining high in ${ }^{13} \mathrm{C}$ during the final growth stage.

For the three localities, the variation of carbon isotope ratios within single diamonds exhibits no correlation with the presence or absence of internal inclusions; for example, both clear diamonds without inclusions and diamonds of IaAB nitrogen aggregation may have large or small internal variations in carbon isotope composition from core to rim (Table 1 and 4). In the current study, the extent of variation of carbon isotope ratios within single diamonds appears to be related to the occurrence of phases of diamond dissolution between growth zones in CL images. Generally, little variation in carbon isotope ratios is observed within single diamonds if no distinct zoning is observed in CL images or if only regular growth zones, not interrupted by dissolution, are present (L2 and QL1 from Liaoning, S3 from Shandong;

Table 4 Variations in $\delta^{13} \mathrm{C}$ for the single diamonds of Liaoning, Shandong, and Hunan

\begin{tabular}{|c|c|c|c|c|c|c|}
\hline \multirow{2}{*}{ Locality } & \multirow{2}{*}{ Sample No. } & \multirow{2}{*}{$\mathrm{N}$ aggregation } & \multicolumn{3}{|c|}{$\delta^{13} \mathrm{C}(\% o)$} & \multirow{2}{*}{$\Delta \delta^{13} \mathrm{C}(\%)$} \\
\hline & & & Maximum & Minimum & Average & \\
\hline \multirow{4}{*}{ Liaoning } & L1 & IaAB-IaB & -5.77 & -2.57 & -3.79 & 3.21 \\
\hline & L2 & IaAB-IaA & -3.99 & -3.51 & -3.73 & 0.48 \\
\hline & L3 & $\mathrm{IaAB}$ & -6.02 & -2.89 & -4.75 & 3.13 \\
\hline & QL1 & $\mathrm{IaAB}$ & -3.50 & -2.92 & -3.16 & 0.58 \\
\hline \multirow{4}{*}{ Shandong } & S1 & IaAB-IaB & -5.14 & -2.40 & -3.26 & 2.75 \\
\hline & S2 & $\mathrm{IaAB}$ & -5.60 & -2.97 & -4.59 & 2.63 \\
\hline & S3 & $\mathrm{IaAB}$ & -5.15 & -4.53 & -4.87 & 0.62 \\
\hline & QS1 & $\mathrm{IaAB}$ & -3.45 & -2.01 & -2.77 & 1.45 \\
\hline \multirow{3}{*}{ Hunan } & $\mathrm{H} 1$ & $\mathrm{IaAB}$ & -8.55 & -5.34 & -7.52 & 3.21 \\
\hline & QH1 & IaAB-IaB & -8.31 & -6.25 & -6.75 & 2.06 \\
\hline & $\mathrm{QH} 2$ & $\mathrm{IaAB}-\mathrm{IaB}$ & -4.36 & -2.99 & -3.47 & 1.37 \\
\hline
\end{tabular}



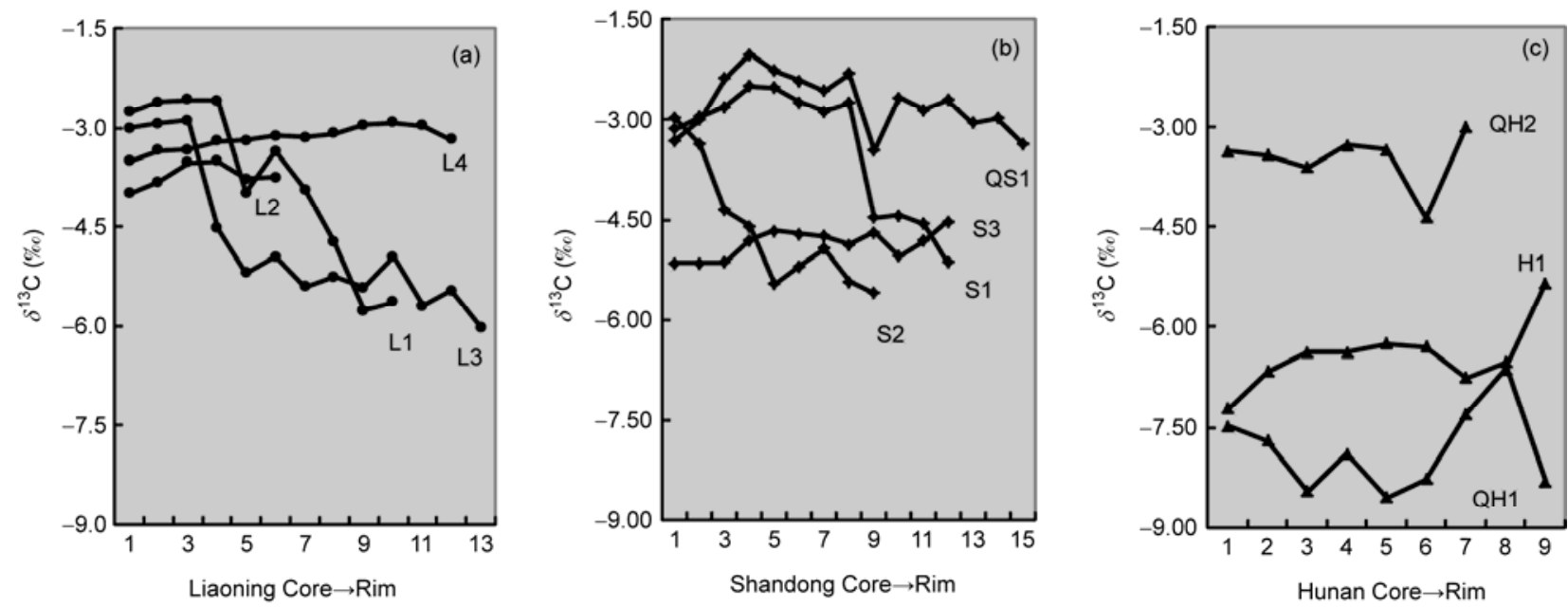

Figure 5 The variations in $\delta^{13} \mathrm{C}(\% \circ)$ along core to rim traverses for single diamonds from Liaoning (a), Shandong (b) and Hunan (c).

and early growth stages in diamonds $\mathrm{QH} 1$ and $\mathrm{QH} 2$ from Hunan). In contrast, diamonds with phases of intermittent dissolution visible in CL images, such as L1 and L3 from Liaoning and S1 from Shandong, have large internal variation of carbon isotope ratios. This suggests that the variations of carbon isotopes in single diamonds were mainly influenced by the chemical composition of the diamond precipitating mantle fluids, but seemed not to be correlated with the presence or absence of inclusions or nitrogen aggregation.

Diamonds from Liaoning and Shandong have carbon isotope ratios $\left(\delta^{13} \mathrm{C}\right)$ ranging between $-6.0 \%$ and $-2.0 \%$ o and concentrating between $-5.5 \%$ and $-3.0 \%$. They may have small internal variation of $0.5 \%$ or a large internal variation of $3.2 \%$ from core to rim. This suggests that the variations of carbon isotopes in diamonds from the North China Craton may be affected by both the heterogeneity of carbon isotope compositions in mantle carbon reservoirs and isotopic fractionation during diamond precipitation $[35,40]$. In contrast, for Hunan diamonds the carbon isotope ratios cover a much wider range from $-8.6 \%$ o to $-3.0 \%$ and mainly between $-6.5 \%$ and $-3.5 \%$, but internal variations in carbon isotope ratios are smaller. Hunan diamonds have lighter carbon isotope ratios in cores than Liaoning and Shandong diamonds. This reflects that carbon of lighter isotopic composition was present during the formation of diamonds in the lithospheric mantle beneath the Yangtze Craton, compared to the North China Craton. For diamonds from all three localities, samples displaying phases of dissolution between growth stages show the greatest variation in carbon isotope ratios and, therefore, it is deduced that the heterogeneity of carbon isotope compositions in the mantle reservoir played a greater role than isotopic fractionation during diamond growth in imposing variations of carbon isotope compositions in diamonds [41,42].

For Hunan there is a similar percentage of diamonds with eclogitic and peridotitic inclusions. Observed inclusion phases include $\mathrm{KCl}, \mathrm{NaCl}$, chromite, omphacite, coesite, and moissanite [35,43]. Mean carbon isotope compositions for whole Hunan diamonds range from $-22.2 \%$ to $-2.5 \%$ o [25]. These observations are consistent with early to late Proterozoic subduction and collision-subduction events within the Yangtze Craton, which may have transported carbon with a crustal isotopic signature into the lithospheric mantle beneath the Yangtze Craton [44-47]. This implies a fundamental difference (e.g. in metasomatic fluids composition) in deep geological processes between the Yangtze Craton and the North China Craton.

\subsection{Variations of carbon isotopes and $\mathbf{N}$ abundances and their implication}

There is still considerable debate about the relationship between $\mathrm{N}$ abundance, carbon isotope composition and nitrogen isotope composition in diamonds. Some researchers claimed that there is little relation between $\mathrm{N}$ abundance and carbon isotope ratios for non-coated diamonds [40,48,49], whereas others $[2,11,17,18]$, based on studies on coated diamonds $[15,17,40]$, claimed that variations of carbon isotope ratios were correlated with $\mathrm{N}$ abundance, $\mathrm{N}$ aggregation state and $\mathrm{N}$ isotope composition. For example, Javoy et al. [12] found that there is a negative correlation between $\delta^{13} \mathrm{C}$ and $\delta^{15} \mathrm{~N}$ for diamonds crystallized in the environment of decreasing $\mathrm{fO}_{2}$ in Mbuji Mayi, Zaire. Bulanova et al. [21] showed the presence of good correlations between $\delta^{13} \mathrm{C}$, $\delta^{15} \mathrm{~N}$ and $\mathrm{N}$ abundance within a diamond from Yakutia $\left(\delta^{13} \mathrm{C}\right.$ and $\delta^{15} \mathrm{~N}$ became heavier, and $\mathrm{N}$ abundance became smaller from core to rim) probably implying isotopic fractionation in a closed environment during a continuous process of crystallization. Ukhanov and Khachatryan [50] showed the $\delta^{13} \mathrm{C}$ of diamonds have inverse co-variations with $\mathrm{N}$ abundance, i.e. the greater $\delta^{13} \mathrm{C}$ values, the lower the $\mathrm{N}$ abun dance. Although there is no consensus about the relationship between $\delta^{13} \mathrm{C}, \delta^{15} \mathrm{~N}$ and $\mathrm{N}$ abundance in single 
diamonds, increasing $f \mathrm{O}_{2}$ in the diamond crystallizing environment may lead to heavier carbon isotope compositions [10] and higher $\mathrm{N}$ abundances [51] in diamonds. Therefore, any clear co-variations in $\delta^{13} \mathrm{C}, \delta^{15} \mathrm{~N}$ and $\mathrm{N}$ abundance in single diamonds reflects continuous crystallization in a relatively closed environment and suggests that carbon isotopes and $\mathrm{N}$ abundances in such diamonds were mainly influenced by fractional crystallization [21].

In our study, variations of carbon isotope ratios from core to rim did not show any correlation with $\mathrm{N}$ abundance for three diamonds from three localities. The results of infrared spectral mapping for 14 diamonds, including diamonds studied in this paper, also show that $\mathrm{N}$ abundances in cores may be greater or smaller than those of outer growth zones of diamonds from the two cratons, and their overall $\mathrm{N}$ abundances display no unidirectional variation, suggesting that complex exchanges occurred between carbon and nitrogen during diamond growth [52]. It is not clear what accounts for such complex patterns. Based on diamonds from three localities, we find that variations in carbon isotopes show no correlation with the presence or absence of inclusions and with $\mathrm{N}$ aggregation, but instead are related to clear structural dissolution and growth boundaries. These results suggest either the presence of complex and heterogeneous carbon and nitrogen reservoirs in the mantle, or that the diamonds grew in an open geochemical environment. The findings in this paper are preliminary, and need further study based on more samples.

\section{Conclusions}

For the first time, in-situ analyses of $\mathrm{N}$ abundance and carbon isotope composition across different growth zones were carried out using Secondary Ion Mass Spectrometry (SIMS) for diamonds from Liaoning and Shandong in the North China Craton and Hunan in the Yangtze Craton, China. The findings obtained are summarized as follows:

(1) The carbon isotope compositions showed various zones from core to rim, corresponding to internal growth zones of diamonds visible in cathodeluminescence. Diamonds from the North China Craton have carbon isotope ratios ranging from $-6.0 \%$ o to $-2.6 \%$, similar to diamonds of peridotitic paragenesis worldwide. Diamonds from the Yangtze Craton show carbon isotope ratios ranging from $-8.6 \%$ o to $-2.6 \%$, similar to eclogitic paragenesis diamonds from worldwide sources. In addition, diamonds from the North China Craton have an average $\delta^{13} \mathrm{C}$ of $-3.0 \%$ during early growth stages, whilst diamonds from Yangzte Craton have $\delta^{13} \mathrm{C}$ depleted values (average $-7.4 \%$ ) during earliest growth. This may indicate that $\delta^{13} \mathrm{C}$ depletion is an inherent property of the subcontinent lithospheric mantle beneath the Yangtze Craton.

(2) In-situ analyses of carbon isotope compositions at different growth zones within single diamond show: (i) that
CL intensities are not correlated with $\delta^{13} \mathrm{C}$ values, and (ii) that variations in carbon isotope ratios are not correlated with the presence or absence of inclusions, or $\mathrm{N}$ abundance and aggregation. Variations in carbon isotope ratios between growth zones are, however, positively correlated with the occurrence of phases of diamond dissolution and new growth, indicating precipitation from mantle fluids with heterogeneous carbon isotope composition. The isotopic heterogeneity of mantle carbon reservoirs obviously played a greater influence than isotopic fractionation on variations in diamond $\delta^{13} \mathrm{C}$.

We thank the two anonymous reviewers for their precious suggestions and comments on this manuscript. We also want to thank the following people for their generous help both in the field work and sample collecting of this project: the former chief engineer, Han Zhuguo, and the present chief engineer, Lin Shaoquan, of No.6 Geological Team of Liaoning Bureau of Geology and Mineral Resources Exploration; Yang Daorong, director of General Engineer Office of No.7 Exploration Institute of Shandong Bureau of Geology and Mineral Resources; two-term chief engineers, Li Ziyun and Dong Bin, for Team 413 of Geology \& Mineral Resources Development Bureau, Hunan Province; finally, we are much obliged to the following three institutions for their help in our field work, No.701 Mine of Shandong Building Materials, Dalian Wafangdian Diamond Company Limited, and Yichang Institute of Geology and Mineral Resources, China Geological Survey. The work was supported by the Public Research Project of the Ministry of Land and Resources of the People's Republic of China (200811012), and the National Natural Science Foundation of China (41272086).

1 Zheng J P, Yu C H, Lu F X, et al. Diamond with multistage growth and its significance for mantle fluid within accreted craton. Earth Sci Front, 2001, 8: 103-109

2 Stachel T, Harris J W, Muehlenbachs K. Sources of carbon in inclusion bearing diamonds. Lithos, 2009, 1125: 625-637

3 Zhang Z, Zhang H F. Diamond and deep carbon cycle. Earth Sci Front, 2011, 18: 268-283

4 Han Y K, An N. A stripping combustion method for the analysis of carbon isotopes in diamonds. Rock and Mineral Anal, 1986, 4: 296-303

5 Chi J S, Lu FX. Features of Paleozoic Lithosphere Mantle and Kimberlites in Huabei Craton. Beijing: Science Press, 1996. 301

6 Guo J G, Cai X C, Deng H X, et al. Ib diamonds of alluvial deposits in Hunan. Chin Sci Bull, 1985, 18: 1403-1405

7 Craig H. The geochemistry of the stable carbon isotopes. Geochim Cosmochim Acta, 1953, 3: 53-92

8 Wickman E. The cycle of carbon and the stable carbon isotopes. Geochim Cosmochim Acta, 1956, 9: 136-153

9 Galimov M. The relation between formation conditions and variations in isotope composition of diamonds. Geochem Inter, 1985, 22: 118-142

10 Deines P. The carbon isotopic composition of diamonds: Relationship to diamond shape, color, occurrence and vapor composition. Geochim Cosmochim Acta, 1980, 44: 943-961

11 Swart P K, Pillinger C T, Milledge H J, et al. Carbon isotopic variation within individual diamonds. Nature, 1983, 303: 793-795

12 Javoy M, Pineau F, Demaiffe D. Nitrogen and carbon isotopic composition in the diamonds of Mbuji Mayi (Zaire). Earth Planet Sci Lett, 1984, 68: 399-412

13 Boyd S R, Mattey D P, Pillinger C T, et al. Multiple growth events during diamond genesis: An integrated study of carbon and nitrogen isotopes and nitrogen aggregation state in coated stones. Earth Planet Sci Lett, 1987, 86: 341-353

14 Galimov E M. Isotope fractionation related to kimberlite magmatism 
and diamond formation. Geochim Cosmochim Acta, 1991, 55: 16971708

15 Boyd S R, Pillinger C T, Milledge H J, et al. C and N isotopic composition and the infrared absorption spectra of coated diamonds: Evidence for the regional uniformity of $\mathrm{CO}_{2}-\mathrm{H}_{2} \mathrm{O}$ rich fluids in the lithospheric mantle. Earth Planet Sci Lett, 1992, 109: 633-644

16 Pearson D G, Boyd S R, Haggerty S E, et al. The characterization and origin of graphite in cratonic lithospheric mantle: A petrological carbon isotope and Raman spectroscopic study. Contrib Mineral Petrol, 1994, 115: 449-466

17 Deines P, Harris J W, Gurney J J. Depth-related carbon isotope and nitrogen concentration variability in the mantle below the Orapa kimberlite, Botswana, Africa. Geochim Cosmochim Acta, 1993, 57: 2781-2796

18 Deines P, Harris J W, Gurney J J. Carbon isotope ratios, nitrogen content and aggregate state and inclusion chemistry of diamond from Jwaneng, Botswana. Geochim Cosmochim Acta, 1997, 61: 3993-4005

19 Harte B, Fitzsimons I, Harris J W, et al. Carbon isotope ratios and nitrogen abundances in relation to cathodoluminescence characteristics for some diamonds from Kaapvaal Province, S Africa. Mineral Mag, 1999, 63: 829

20 Zedgenizov D A, Harte B, Shatsky V S, et al. Directional chemical variations in diamonds showing octahedral following cuboid growth. Contrib Mineral Petrol, 2006, 151: 45-57

21 Bulanova G P, Pearson D G, Hauri E H, et al. Carbon and nitrogen isotope systematic within a sector-growth diamond from the Mir kimberlite, Yakutia. Chem Geol, 2002, 188: 105-123

22 Smith C B, Bulanova G P, Kohn S C, et al. Nature and genesis of Kalimantan diamonds. Lithos, 2009, 112: 822-832

23 Liu G L, Wang H W. Discussion on the geological forming condition of tape II diamond. Bull Yichang Inst Geol Mineral Resources, CAGS, 1989: 41-81

24 Zhang H F, Lu F X, Zhao L, et al. Carbon isotopes in China natural diamonds. J China Univ Geosci, 2009, 34: 37-42

25 Liu G L, Han Y K, Zhai L N, et al. Carbon isotopic composition and genesis of diamond. Bull Yichang Inst Geol Mineral Resour, CAGS, 1994, 20: 1-16

26 Welbourn C M, Cooper M, Spear P M. De Beers natural versus synthetic diamond verification instruments. G \& G, 1996, 32: 156-169

27 Kitawaki H, Abduriyim A, Okano M. Identification of melee-size synthetic yellow diamonds in jewelry. G \& G, 2008, 44: 202-213

28 Hall H T. Ultra-high pressure apparatus. Rev Sci Instrum, 1960, 31: 125

29 Bovenkerk H P, Bundy F P, Hall H T, et al. Preparation of diamond. Nature, 1959, 184: 1094

30 Hazen R M. The Diamond Makers. Cambridge: Cambridge University Press, 1999

31 Sunagawa I. Morphology of natural and synthetic diamond crystals. In: Sunagawa I, ed. Materials Science of the Earth's Interior. Tokyo: Terra scientific Publishing Co, 1984. 303-330

32 Orlov Y. The Mineralogy of Diamond. New York: John Wiley and Sons, 1973. 264

33 Xiao H Y, Liu C Q, Huang Z L. Information of old mantle from inclusions in diamonds. Adv Earth Sci, 2001, 16: 244-250

34 Lu T J, Chen H, Qiu Z L, et al. Multiple core growth structure and nitrogen abundances of diamond crystals from Shandong and Liao- ning kimberlite pipes, China. Eur J Mineral, 2012, 24: 651-656

35 Chen M H, Lu F X, Zheng J P. Cathodoluminescence features of diamond in Fuxian, Liaoning province and their implications. J Chin Univ Geosci, 1999, 24: 179-182

36 Chen M H, Lu F X, Di J R, et al. Cathodoluminesence and FTIR analysis in the diamonds of Wafangdian, Liaoning Province of China. Chin Sci Bull, 2000, 45: 1424-1428

37 Cartigny P. Stable isotopes and the origin of diamond. Elements, 2005, 1: 79-84

38 Stepanov A S, Shatsky V S, Zedgenizov D A, et al. Causes of variations in morphology and impurities of diamonds from the Udachnaya Pipe eclogite. Russ Geol Geophys, 2007, 48: 758-769

39 Liu Y, Taylor L A, Sarbadhikari A B, et al. Metasomatic origin of diamonds in the world's largest diamondiferous ecologite. Lithos, 2009, 112: 1014-1024

40 Chen M H, Li Y, Di J R, et al. Agate-like structure and heterogeneities of nitrogen and hydrogen impurities of diamond in Mengyin, China. Acta Geol Sin, 2006, 80: 1197-1201

41 Chu C L. Carbon isotopes in mantle. Adv Earth Sci, 1996, 11: 446452

42 Zheng Y F. Mantle stable isotope geochemistry (in Chinese). In: Zheng Y F, ed. Chemical Geodynamics. Beijing: Science Press, 1999. 62-118

43 Chen H, Qiu Z L, Lu T J, et al. The Research on "fingerprint" Characteristics and the Geographic Origin of Diamonds Under the United Nations' Kimberley Process Framework. Beijing: Geological Publishing House, 2012 (in press)

44 Li X H, Zhao J X, MeCulloeh M T, et al. Geochemical and Sm-Nd isotopic of Neoproterozoic ophiolites from southeastern China: Petrogenesis and tectonic implications. Precambriam Res, 1997, 81: 129-144

45 Ding B H, Shi R D, Zhi X C, et al. Neoproterozoic ( 850 Ma) subduction in the Jiangnan orogen: Evidence from the SHRIMP U-Pb dating of the SSZ-type ophiolite in southern Anhui Province. Acta Petrol Mineral, 2008, 27: 375-388

46 Zheng Y F, Wu F Y. Growth and reworking of cratonic lithosphere. Chin Sci Bull, 2009, 54: 1945-1949

47 Liu C Z, Liu Z C, Wu F Y, et al. Mesozoic accretion of juvenile sub-continental lithospheric mantle beneath South China and its implications: Geochemical and Re-Os isotopic results from Ningyuan mantle xenoliths. Chem Geol, 2012, 292: 186-198

48 Harte B, Otter M L. Carbon isotope measurements on diamonds. Chem Geol, 1992, 101: 177-183

49 Fitzsimons I C W, Harte B, Chinn J J, et al. Extreme chemical variation in complex diamonds from George Creek, Colorado: A SIMS study of carbon isotope composition and nitrogen abundance. Min Mag, 1999, 63: 857-878

50 Ukhanov A V, Khachatryan G K. Carbon isotope and Ir evidence in favor of fluid origin of natural diamonds from kimberlite pipes in Yakutian Province. In: 9th International Kimberlite Conference Extended Abstract, 2008. 1-2

51 Deines P, Harris J W, Spear P M, et al. Nitrogen and ${ }^{13} \mathrm{C}$ content of Finch and Premier diamonds and their implications. Geochim Cosmochim Acta, 1989, 53: 1367-1378

52 Sun Y, Qiu Z L, Lu T J, et al. Micro-FTIR mapping tracer for the heterogeneity growth of nitrogen impurities in natural diamond from three localities in China. Spectrosc Spect Anal, 2012, 32: 2070-2074

Open Access This article is distributed under the terms of the Creative Commons Attribution License which permits any use, distribution, and reproduction in any medium, provided the original author(s) and source are credited. 